\title{
O CARD SORTING NO ENSINO DE BIBLIOTECONOMIA: UMA EXPERIÊNCIA EM SALA DE AULA
}

\author{
THE CARD SORTING IN LIBRARY SCIENCE EDUCATION: \\ AN EXPERIENCE IN THE CLASSROOM
}

\begin{abstract}
Viviane de Oliveira Solano ${ }^{1}$ Janicy Aparecida Pereira Rocha ${ }^{2}$

\section{RESUMO}

Este artigo demonstra a experiência na aplicação da técnica do Card Sorting em sala de aula no âmbito de duas disciplinas da graduação em Biblioteconomia, na Escola de Ciência da Informação da Universidade Federal de Minas Gerais: Modelagem conceitual a partir dos princípios de Ranganathan e Arquitetura de informação e acessibilidade digital. Foram utilizados os aportes da categorização no contexto da Organização da Informação, salientando elementos que subsidiam a discussão em torno do delineamento do Card Sorting. Percebeu-se que é importante o entendimento e domínio da técnica supracitada para os profissionais da informação atuarem no tratamento, categorização e organização da informação em ambientes informacionais digitais como também, na estruturação do fluxo navegacional nesses ambientes. Do ponto de vista do ensino de Biblioteconomia e Ciência da informação, a experiência mostrou o potencial de uma prática interdisciplinar, na execução de trabalhos integrativos e de parceria entre diferentes disciplinas.
\end{abstract}

PALAVRAS-CHAVE: Card Sorting. Organização da informação. Categorização. Ensino.

\begin{abstract}
This article demonstrate the experience in the application of Card Sorting technical's at the classroom, in a context of two courses of undergraduate Library Science, School of Information Science at the Federal University of Minas Gerais: Conceptual modeling based on the principles Ranganathan and Information Architecture and Digital Accessibility. The contributions of categorization were used in the context of Information Organization, highlighting elements that support the discussion on the design of the Card Sorting. It was noticed that are essential understanding and mastery of the aforementioned technique for information professionals will engage in treatment, categorizing and organizing information into digital information environments but also in structuring the navigational flow of these environments. From the point of view of the teaching of Library and Information Science, experience has shown the potential for interdisciplinary practice in the implementation of integrative work and partnership between different disciplines.
\end{abstract}

KEYWORDS: Card Sorting. Information organization. Categorization. Education.

\section{INTRODUÇÃO}

A Organização da Informação é um conceito que tem sido amplamente discutido e desenvolvido no contexto da Biblioteconomia e da Ciência da Informação. É considerado um assunto complexo na medida em que tem a representação de objetos (físicos ou digitais) como base principal. De acordo com Alvarenga (2003), para que a representação ocorra, é necessário que os profissionais da informação desenvolvam e implementem sistemas

\footnotetext{
1 Universidade Federal de Minas Gerais - Escola de Ciência da Informação. Embrapa Pantanal. E-mail: solano.viviane@gmail.com

${ }^{2}$ Universidade Federal de Minas Gerais - Escola de Ciência da Informação. E-mail: janicy.rocha@gmail.com

Recebido em: 23/06/2014 - Aceito em: 06/05/2015
} 
representacionais que estabeleçam a confluência entre a organização cognitiva imposta ao conhecimento pelo seu produtor (representação primária) e a organização conceitual imposta ao documento pelo especialista da informação (representação secundária).

A problemática da representação de objetos e da organização de conteúdos remete à dificuldade em ensinar tal prática, o que exige maior esforço e certa criatividade por parte dos educadores. Conforme Rodrigues e Campelo (2004) o ensino e aprendizagem em Biblioteconomia e Ciência da Informação (BCI) necessita de uma proposta pedagógica diferenciada que proporcione aos educandos condições para enfrentar com proficiência os problemas de sua prática profissional e refletir criticamente sobre a realidade que os envolve.

Nessa perspectiva, entende-se que o professor é demandado a criar condições que possibilitem ao aluno aprender a traçar estratégias e desenvolver habilidades para resolver problemas; usar conhecimentos disponíveis para enfrentar novas situações; saber trabalhar em equipe; respeitar e valorizar a opinião e o trabalho dos outros (COLL et al., 2000). Diante de tais situações, faz-se necessário que o educador inove em sua proposta de ensino, selecionando métodos e técnicas que contribuam para o aprendizado dos alunos.

O Card Sorting é uma técnica que tem se mostrado bastante válida para explorar e compreender como os usuários organizam conteúdos relacionados a determinado domínio, tanto no ambiente digital quanto no físico. Nesta linha de raciocínio, destaca-se o uso desta como uma boa alternativa para o ensino referente à Organização da Informação (OI), já que permite o entendimento de terminologias (como as pessoas nomeiam as coisas), relações (de proximidade ou similaridade) e categorias (grupos e seus nomes) (HUDSON, 2013).

Diante do exposto, o presente artigo tem como objetivo relatar a experiência na aplicação da técnica do Card Sorting em sala de aula no ensino de duas disciplinas da área de BCI. Para tal, sua estrutura foi delineada incorporando as seguintes seções: o contexto das disciplinas em que foi aplicado o Card Sorting; a caracterização da técnica; seu uso no contexto da organização da informação; a experiência na condução da aplicação e, por fim, as considerações finais.

\section{O CONTEXTO DAS DISCIPLINAS}

No primeiro semestre de 2014 foram ofertadas duas disciplinas optativas como estágio docente ${ }^{3}$, para a graduação em Biblioteconomia, na Escola de Ciência da Informação da Universidade Federal de Minas Gerais (ECI/UFMG); ambas com carga horária de 60 horas/aula. As aulas ocorriam uma vez por semana, às terças-feiras, em encontros de 4 horas/aula. Nelas se matricularam alunos do $7^{\circ}$ período. A maioria destes alunos ingressou na graduação em uma mesma turma, entretanto, esta foi dividida, após a opção dos alunos entre

\footnotetext{
${ }^{3}$ No Programa de Pós-Graduação em Ciência da Informação da Universidade Federal de Minas Gerais (PPGCI/UFMG) mestrandos e doutorandos propõem e ministram disciplinas optativas para cursos de graduação da ECI/UFMG, sob supervisão de seus orientadores ou de professores por eles designados, conforme Resolução 05/2013 (UNIVERSIDADE..., 2013).
} 
uma das duas disciplinas, caracterizadas adiante.

Uma das disciplinas, denominada Modelagem conceitual a partir dos princípios de Ranganathan, foi ministrada pela mestranda Viviane Solano e contou com 14 alunos matriculados. Teve como objetivo analisar os principais elementos do modelo conceitual de Ranganathan e sua utilização na modelagem de um domínio, discutindo a adequação destes elementos para representar diferentes situações da realidade. Para tanto, o conteúdo programático compreendeu a representação e organização do conhecimento: Sistemas de Organização do Conhecimento (SOCs); categorização e relacionamentos entre termos/conceitos; teoria da classificação facetada, método de análise facetada e categorias fundamentais Personalidade, Matéria, Energia, Espaço e Tempo (PMEST) de Ranganathan; conceitos e princípios da modelagem conceitual e introdução à prática da modelagem de um domínio.

A segunda disciplina, denominada Arquitetura de Informação e Acessibilidade Digital, foi ministrada pela doutoranda Janicy Rocha e teve 12 alunos matriculados. O objetivo foi fornecer uma visão geral sobre a Arquitetura da Informação e acessibilidade em ambientes informacionais digitais, perpassando pelos conceitos básicos, leis, diretrizes e padrões que orientam estas práticas. Para tanto, o conteúdo programático foi distribuído em: a Arquitetura da Informação; acessibilidade digital, acessibilidade na internet e acessibilidade web; Design Universal, usabilidade; pessoas com deficiência; Tecnologia Assistiva; estudos de uso e usuários para avaliação de interfaces e relações entre Arquitetura da Informação, acessibilidade e biblioteconomia.

Apesar de possuírem ementas distintas, as autoras perceberam semelhanças nas abordagens das duas disciplinas. Ambas forneceram instrumental para o ensino de organização e categorização da informação em quaisquer ambientes (físico ou digital), o que justifica o motivo da integração das turmas para a realização da atividade. Na Seção 3 é revisada a técnica do Card Sorting e na Seção 4 a mesma é relacionada à OI, temática que perpassou as duas disciplinas.

\section{CARD SORTING: A TÉCNICA}

Derivado da técnica denominada Kelly Grid $^{4}$, desenvolvida para estudos de modelos conceituais em psicologia, o Card Sorting foi adaptado para identificação de atores externos em organizações não governamentais por Davies (1996). Desde então, seu uso tem se intensificado, sobretudo no âmbito da Arquitetura da Informação direcionada a ambientes digitais ou não.

Santa Rosa e Moraes (2012) apontam que aplicação do Card Sorting tem como propósitos identificar a terminologia que usuários compreendem mais facilmente, os itens difíceis de classificar e as informações que possam pertencer a mais de um grupo, além de

\footnotetext{
${ }^{4}$ Técnica desenvolvida em 1955 pelo psicólogo George A. Kelly com o objetivo de descrever as formas pelas quais as pessoas dão sentido à sua experiência em seus próprios termos (GRAHAM, 2007).
} 
perceber como diferentes públicos-alvo categorizam o conteúdo e como cada perfil de usuário pode acessar determinado conteúdo.

Duas modalidades de aplicação do Card Sorting foram propostas por Rosenfeld e Morville (2006). Na primeira modalidade, denominada forma aberta ou bottom-up, os participantes recebem cartões em branco nos quais escrevem termos para nomear as categorias e os classificam em seguida. Na segunda, tem-se a forma fechada ou top-down. Nesta, os participantes recebem os cartões já nomeados e apenas os organizam. As duas modalidades possuem como objetivo final a construção de uma estrutura hierárquica do conteúdo informacional, organizado a partir do ponto de vista dos usuários.

A condução da aplicação de Card Sorting envolve três etapas: planejamento; aplicação e discussão (CYBIS; BETIOL; FAUST; 2007; FARIA, 2010). Na etapa de planejamento, a preparação dos materiais para o uso (cartões, fitas adesivas, canetas) e a seleção dos participantes que devem representar o público-alvo do ambiente informacional são atividades comuns nas duas modalidades.

$\mathrm{Na}$ etapa de aplicação, os participantes do Card Sorting aberto, identificam e escrevem os nomes dos objetos nos cartões, organizando-os hierarquicamente. Já no Card Sorting fechado, os participantes apenas organizam, em categorias e subcategorias, os cartões recebidos, nos quais já constam os nomes dos objetos. Nessa modalidade também é permitida a criação e a inserção de novos termos e/ou o isolamento de cartões que não se encaixam na estrutura hierárquica. Entretanto, é necessário que estas escolhas sejam devidamente justificadas.

Na etapa de discussão, cada participante (ou grupo) explica a lógica utilizada na organização dos cartões e apresenta suas justificativas para inclusão ou retirada de cartões. Também são discutidos termos que se mostraram de difícil compreensão (por serem ambíguos, possuírem vários significados ou serem pouco conhecidos, dentre outros) e propostas para substituições. Em seguida, as diversas estruturas são comparadas e, consensualmente, é definida a melhor estrutura a ser utilizada no ambiente informacional.

Salienta-se que nem sempre a estrutura definida de forma consensual pelos participantes é utilizada integralmente pelos projetistas/desenvolvedores do ambiente informacional. Alterações podem ser feitas, caso seja necessário, mas a estrutura geral montada pelos usuários deve ser mantida para mitigar possíveis dificuldades no uso do ambiente informacional.

\section{O CARD SORTING NA ORGANIZAÇÃO DA INFORMAÇÃO}

Dentro de certo estudo, Ortega (2013) explicita que a Organização da Informação pode ser vista em quatro níveis de manifestação: conceitual, procedimental, tecnológico e aplicado. O nível conceitual refere-se aos conceitos básicos adotados para processos, instrumentos e produtos. $\mathrm{O}$ procedimental trata das metodologias para construção e uso dos 
instrumentos. No tecnológico se dá a viabilização dos processos por meio das ferramentas existentes a cada época. Por último, tem-se o nível das aplicações concretas, como as da prática profissional e das pesquisas experimentais.

É dentro deste panorama que pode ser contextualizada a técnica do Card Sorting, aplicada como uma metodologia de ensino nas disciplinas aqui mencionadas. Entende-se que seu uso perpassou os quatro níveis citados. Na medida em que propõe a execução do exercício mental, subjetivo e interdisciplinar, a técnica envolve a prática pedagógica do ensino e aprendizagem no cenário da organização da informação (níveis conceitual e procedimental). Ao contribuir para a elaboração de produtos e serviços de informação, como por exemplo, a estruturação e a organização de conteúdo em websites, envolve os níveis tecnológico e aplicado.

As categorias estão na base de todo o sistema de organização da informação. Segundo Campos e Gomes (2003), quando se faz uma categorização, está-se analisando um domínio a partir de recortes conceituais que permitem determinar a identidade dos conceitos que fazem parte deste domínio. Conforme explicitam Silva e Lima (2011) a categorização é o processo cognitivo de compreensão das características dos objetos por critérios de similitude ou dessemelhança e constitui-se, na BCI, como uma ação intrínseca à organização dos registros do conhecimento.

Sabe-se que a escolha de nomes para as categorias e a inserção do conteúdo naquela em que ele melhor se enquadra não é um procedimento trivial. Além disso, não é fácil decidir pela criação de subcategorias e pela melhor forma de organizá-las. É primordial o conhecimento do domínio para o qual será construído o ambiente informacional, bem como do contexto em que ele se insere e, sobretudo, de seus usuários. Envolver os usuários no processo de concepção e desenvolvimento da estrutura de um ambiente informacional reduz o risco de falha. Tal contribuição aumenta de forma proporcional ao conhecimento do usuário sobre o domínio a ser modelado.

Dentre os diversos tipos de problemas que podem afetar a usabilidade de um ambiente informacional digital, grande parte está estreitamente relacionada com a organização das informações por ele oferecidas. Combinar e agrupar itens de informação ou objetos, de forma que faça sentido para os usuários é fundamental para a aceitação de um ambiente informacional. A incapacidade de encontrar uma informação é um dos fatores que mais frustram os usuários, muitas vezes levando-os a desistir da busca (ROSENFELD; MORVILLE, 2006).

Quando a organização do conteúdo não é coerente com o modelo mental de seus usuários; os objetos não se encontram dispostos no local esperado por eles ou o nome atribuído a uma categoria possui sentidos diversos, a localização de determinada informação tende a atingir alto grau de dificuldade. Assim, quando há grande instabilidade nos métodos de organização, o alcance da informação significativa tende a se tornar menos efetivo (SILVA; LIMA, 2011). 
Com intuito de organizar a informação, existem diversas aplicações e adaptações das modalidades do Card Sorting, elaboradas de acordo com a necessidade ou objetivo do projeto, como apontam estudos recentes encontrados na literatura. O estudo de Vilela, Carvalho e Fagundes (2009) teve como objetivo apresentar a utilização do Card Sorting na avaliação da usabilidade, durante o desenvolvimento de uma proposta para um sistema de Balanced Scorecard (BSC) $)^{5}$ voltado para instituições de ensino superior. Os autores tomaram como base os conceitos de Arquitetura de Informação para planejar, organizar e estruturar a informação. Como resultados, no que diz respeito à Arquitetura de Informação, o Card Sorting norteou os sistemas de Organização e Rotulação. Quanto à arquitetura do sistema de Balanced Scorecard, a técnica auxiliou na criação da estrutura organizacional que foi direcionada de acordo com o modelo mental do público-alvo.

O artigo de Sá (2013) mostra a metodologia de ensino usada na disciplina de Arquitetura de Informação do curso de Biblioteconomia e Gestão de unidades de informação da Universidade Federal do Rio de Janeiro. A técnica de Card Sorting foi utilizada para entender como os usuários agrupam as informações de acordo com suas relações de característica e significância, dentro do escopo de aprendizado do bibliotecário. A autora concluiu que a informação na internet é um amplo nicho para estes profissionais, principalmente com relação ao tratamento e organização da informação em websites.

Já Padovani e Ribeiro (2013) adaptaram a técnica de Card Sorting para aplicação a sistemas de informação não digitais. O Card Sorting passou por uma combinação de conceitos, métricas e procedimentos para então ser aplicado a três sistemas diferentes: embalagem alimentícia, manual de instruções de eletrodoméstico e mapa turístico impresso. Ao final, os autores vislumbraram a ampliação do escopo do Card Sorting, envolvendo também a ordenação e hierarquização (e não apenas o agrupamento) e a aplicação por pesquisadores não envolvidos no processo de adaptação da técnica.

A exemplo dos estudos citados, na próxima seção é apresentada a experiência da aplicação do Card Sorting nas turmas de Biblioteconomia na Escola de Ciência da Informação da UFMG.

\section{A EXPERIÊNCIA NA CONDUÇÃO DO CARD SORTING}

A aplicação do Card Sorting no ensino e aprendizagem teve como objetivo mais amplo desenvolver nos participantes uma visão crítica, necessária para a atuação na organização de conteúdos de maneira a ser útil para os usuários. Nielsen (2004) alerta que um grave erro em websites e intranets é estruturar a informação da forma como ela é entendida pela própria empresa ou pelo profissional que a organizou, o que nem sempre é condizente com a forma de pensar dos usuários.

\footnotetext{
5 Ferramenta de planejamento estratégico na qual a entidade tem claramente definidas as suas metas e estratégias, visando medir o desempenho empresarial através de indicadores quantificáveis e verificáveis.
} 
Além de demonstrar para os alunos que o mesmo conjunto de informação pode ser organizado de diversas formas, a atividade ainda promoveu a discussão sobre os desafios da categorização, tais como: ambiguidade e heterogeneidade dos conteúdos; diferentes perspectivas que afetam a organização da informação; necessidade de falar a linguagem do usuário e respeitar as políticas internas das organizações que influenciam o processo e a necessidade de que o ambiente informacional seja funcional e agradável esteticamente.

A atividade foi realizada no dia 11 de março de 2014, em sala de aula. Inicialmente, as professoras realizaram uma aula expositiva com o intuito de possibilitar a todos os alunos o entendimento da técnica e de sua aplicação, além de identificar conhecimentos prévios da turma. Na sequência, procedeu-se à operacionalização da técnica, com as seguintes etapas:

1) separação da turma em cinco grupos;

2) entrega da lista de instruções com 53 termos a serem categorizados (Apêndice 1);

3) delimitação do espaço físico para uso de cada grupo, e entrega de cartões e fitas adesivas para fixação nas paredes da sala de aula.

As instruções conduziram os alunos a discutir e decidir, a partir do consenso do grupo, a melhor forma de categorizar os termos recebidos. Caso realmente julgassem necessário, os alunos poderiam criar outros termos/cartões, desde que apresentassem justificativas ao final. E ainda, alguns termos poderiam ser isolados, caso o grupo os considerassem desnecessários, redundantes ou que não se encaixavam em nenhuma categoria.

Foi destacado que os integrantes de um grupo não deveriam ter contato com integrantes de outros, para não fossem influenciados no momento da categorização. O tempo máximo destinado para a conclusão da atividade foi de 60 minutos, com 10 minutos para exposição da estrutura proposta por cada grupo, seguida de discussão.

É importante ressaltar que, ao contrário do que é frequentemente colocado para a realização da atividade do Card Sorting, os alunos não foram informados sobre qual domínio estavam modelando para evitar certo direcionamento intencional na atividade. As professoras acreditavam que pela reflexão dos termos a serem categorizados, eles conseguiriam definir o domínio e organizá-lo conforme suas percepções. Ao final da atividade, no momento da exposição de cada grupo, os integrantes foram questionados sobre que domínio foi pensado no momento da categorização.

$\mathrm{Na}$ execução da atividade (Figura 1), como previsto, ocorreram várias discussões e negociações por parte dos alunos, quanto aos significados e localização de diversos termos. De uma maneira em geral, os estudantes mostraram que sabiam eleger as categorias principais e suas respectivas subcategorias, estabelecendo relações lógicas. 

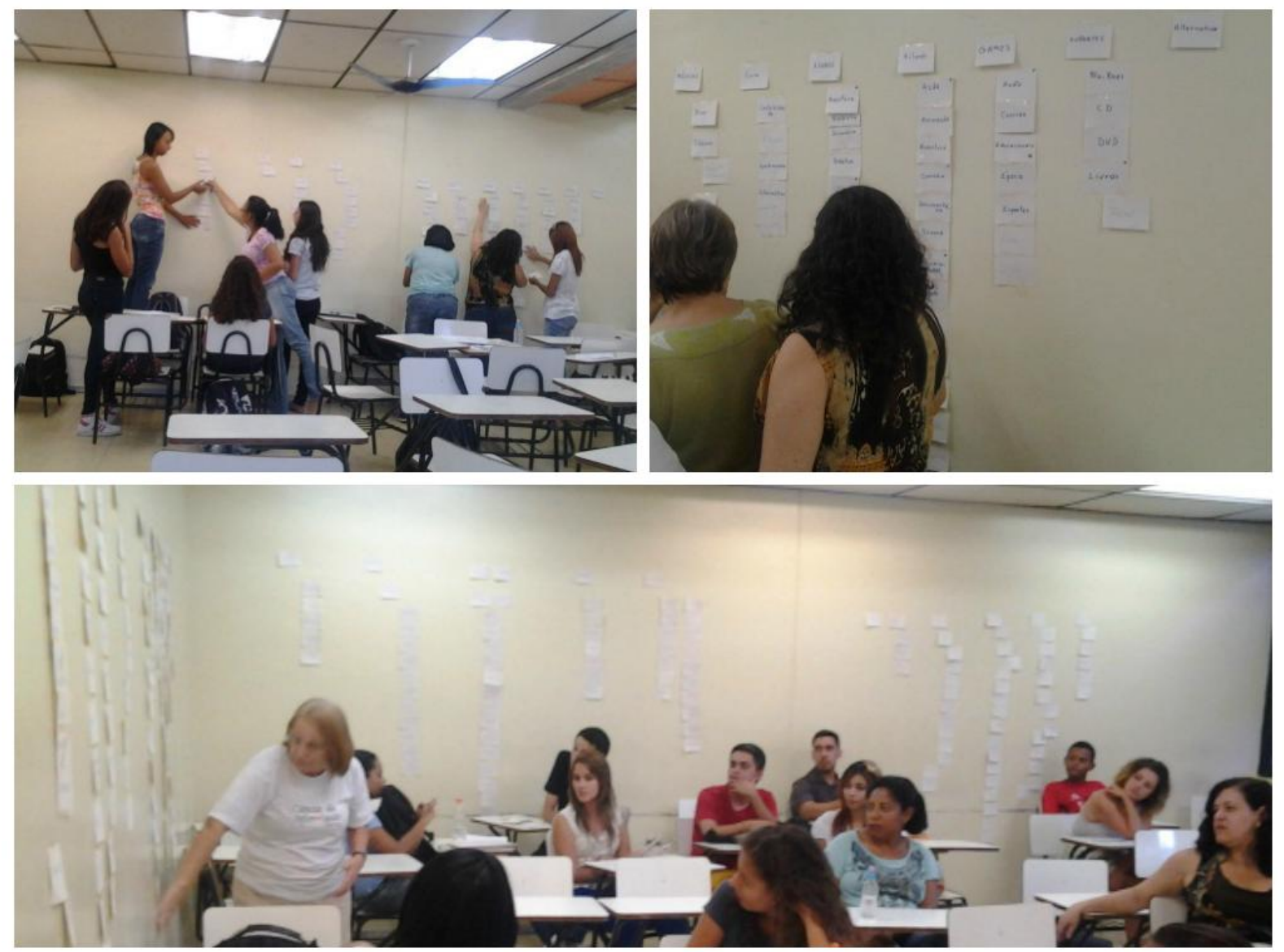

FIGURA 1 - Realização do Card Sorting.

Fonte: Rocha; Solano (2014)

Foram notadas algumas similaridades e diferenças nos resultados dos trabalhos. As estruturas hierárquicas, apesar de diferirem em detalhes, continham todos os termos da listagem. Nenhum grupo inseriu novos termos ou isolou cartões. Entretanto, alguns termos foram duplicados, como pertencentes a mais de uma categoria. De acordo com a percepção de alguns grupos, a categoria Filmes poderia ter DVD e Blu-Ray como subcategorias e nestas estariam duplicados os diferentes gêneros de filmes, com está exemplificado no diagrama apresentado na Figura 2.

Ressalta-se que, considerando a organização da informação em ambientes digitais, duplicar subcategorias é uma prática comumente usada. Nesse ambiente, o uso de hiperlinks permite que sejam feitas mais de uma referência a um mesmo objeto. Essa prática facilita a localização de determinado item pelos usuários e é adotada, sobretudo, para organizar itens que podem se encaixar em mais de uma categoriza/subcategoria. Ao duplicar esses objetos, os alunos afirmaram que tinham em mente a modelagem de uma livraria no ambiente digital. 


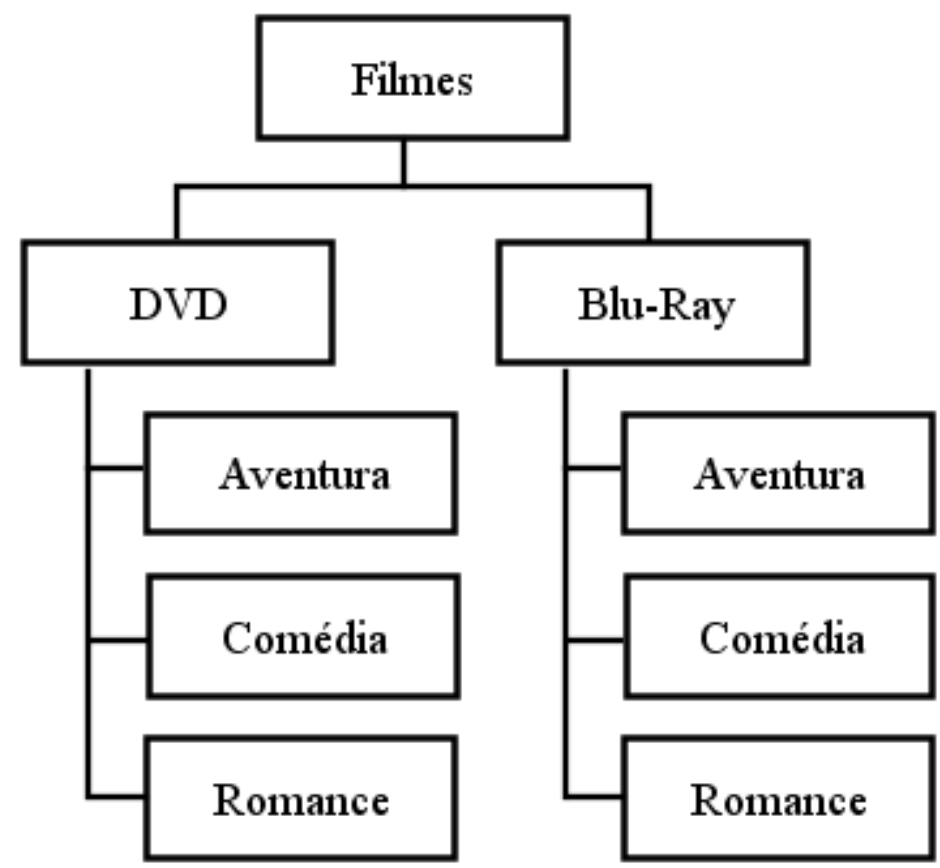

FIGURA 2 - Exemplo de categorização realizada por alguns grupos.

Fonte: Elaborado pelas autoras com base na atividade em sala de aula.

Destaca-se a diferenciação estrutural em que alguns grupos privilegiaram o suporte como categoria (CD, livro, DVD, Blu-Ray) em detrimento das diferentes tipologias (filmes, novelas, games) ou o inverso. Estas escolhas eram feitas a partir de determinada concepção que os grupos tinham de seus usuários e com isso, consideravam as intenções e o comportamento de busca dos mesmos na utilização do ambiente informacional.

Alguns grupos tiveram dificuldades em categorizar alguns termos. O termo Blu-Ray gerou dificuldade pelo fato de alguns alunos não terem seu significado consolidado enquanto suporte. Os termos HQs (Histórias em Quadrinhos), RPG (Role-playing Game) e Pocket (livro de bolso) também geraram discussões pela falta de consenso ou divergências em relação às suas definições. Nesses momentos, eram percebidas longas discussões dentro de cada grupo, em busca de consenso sobre o local onde aquele termo ficaria melhor inserido.

Um grupo se destacou na atividade, talvez pela oportunidade de terem a lousa como apoio para o trabalho ou talvez a partir da diferenciação no que se refere à experiência prévia em categorização. Eles denominaram o seu domínio como Livraria Os 3 Mosqueteiros e expuseram de forma bem delineada sua estrutura, modelando-o em formato de um website fictício, incluindo endereço eletrônico, serviço Fale conosco, ícones de acesso rápido, dentre outros (Figura 3). 


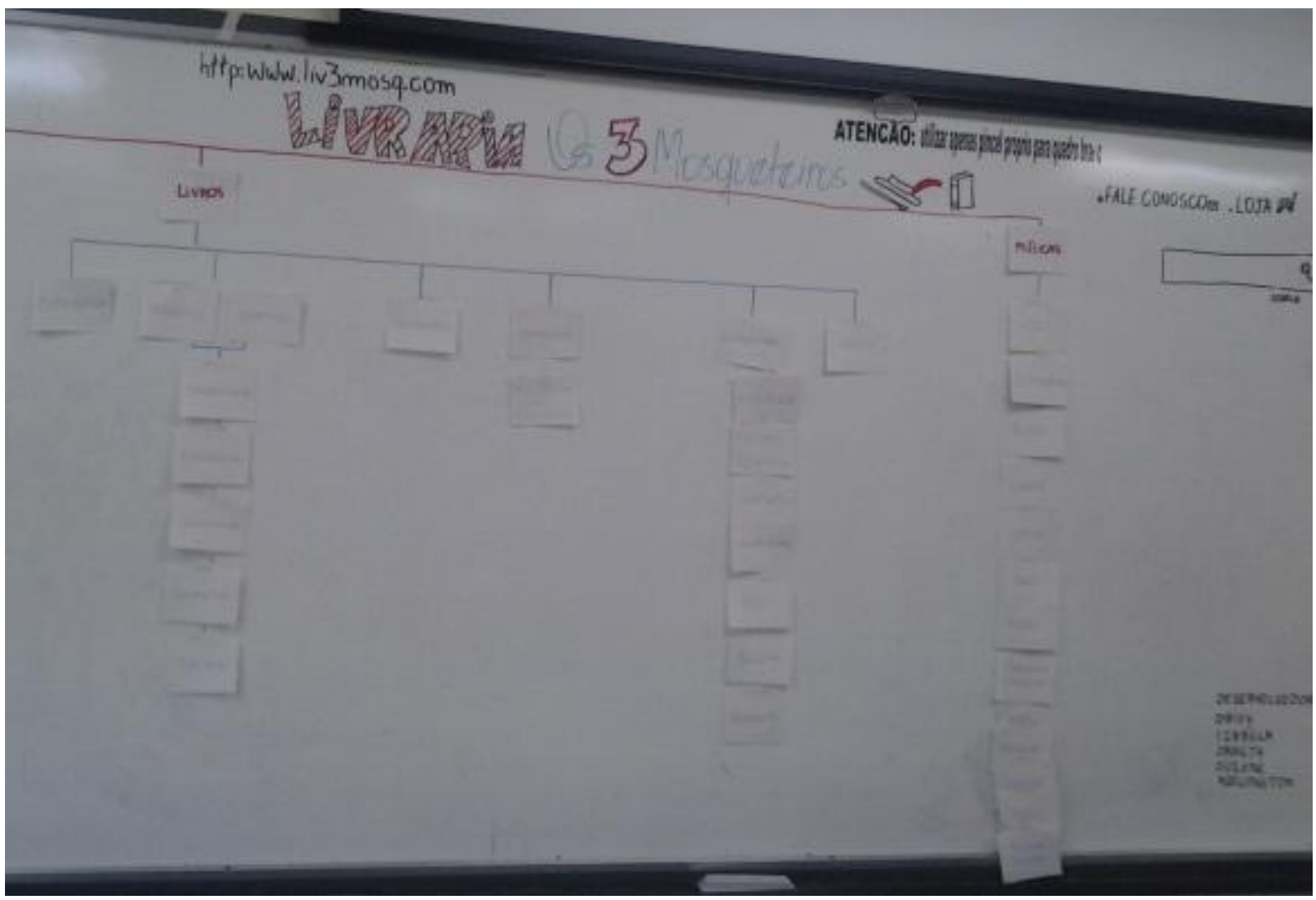

FIGURA 3 - Estrutura da Livraria virtual 'Os 3 mosqueteiros'

Fonte: Rocha; Solano (2014)

Nota-se que apesar da concretude metodológica seguida, ocorreram divergências quanto à inserção e posicionamento dos mesmos termos em estruturas pensadas pelos grupos. Considerando que existem diversas formas de se categorizar e classificar o mesmo conteúdo, não há razões para julgar alguma como certa ou errada. Como professoras das disciplinas e instrutoras da atividade, é possível assegurar que nada foi atestado sobre a correção das disposições hierárquicas elaboradas pelos alunos. Foi esclarecido e enfatizado a respeito da existência de esquemas mais ou menos adequados que ensejam representar um contexto e/ou domínio e atingir determinado público. Todavia, nesse caso, não se almejava a organização mais adequada e sim, o exercício cognitivo para o aprendizado da categorização e da organização. Sendo assim, a análise e a reflexão sobre a atividade ocorreu em consonância com o exposto por Coll et al. (2000):

Trata-se de colocar a ênfase mais sobre os processos que sobre o produto, mais sobre a maneira como as coisas vão sendo feitas pelos alunos que sobre o que é realizado. É nisso que reside a maior significado do ensino dos procedimentos, seja qual for o método adotado (COLL et al., 2000, p.112).

O ensino através das aulas, de certo, é significativo. Todavia, é notório que há uma vasta lacuna entre o que o professor ensina e o que o aluno aprende realmente. A aprendizagem é algo bem maior que deve ocorrer no aluno. Nessa direção, pode-se dizer que a atividade do Card Sorting serviu como ponto de partida para o aprendizado que prioriza a 
prática como complemento às aulas expositivas. A atividade, da forma como foi realizada, contribuiu para o questionamento e a discussão sobre o significado e a coerência das relações lógicas que compõem uma estrutura de um sistema de organização de informação. E assim, propiciou ao aluno se empenhar na conexão de suas ideias de forma que o professor perceba uma postura calcada num traço argumentativo linear.

\section{CONSIDERAÇÕES FINAIS}

O Card Sorting se apresentou como uma técnica de fácil aplicação na medida em que potencializou o discernimento, contextualização e integração de saberes entre os alunos. Como pode ser aplicado em grupos, permite que sejam trabalhadas não apenas as habilidades do aluno referentes à categorização e organização, mas também aquelas referentes ao trabalho em equipe.

Além de ter contribuído para o processo ensino aprendizagem referente à OI, também preparou os alunos para que sejam eles os aplicadores da técnica em suas vivências profissionais. $\mathrm{O}$ entendimento e domínio da técnica supracitada são importantes para que os profissionais da informação atuem no tratamento, categorização e organização da informação em ambientes informacionais digitais. O uso do Card Sorting também auxilia na estruturação do fluxo navegacional dos ambientes informacionais digitais impactando positivamente em sua usabilidade.

Finalmente, salienta-se que, do ponto de vista do ensino de Biblioteconomia e Ciência da Informação, a experiência mostrou o potencial de uma prática interdisciplinar. Nesse sentido, executar trabalhos integrativos e de parceria entre diferentes disciplinas, ensejando um processo de desenvolvimento conjunto, enriqueceu a relação ensino-aprendizagem. Por fim, os aspectos positivos observados reforçam uma experiência bem sucedida, no entanto, não impedem que a atividade aqui relatada seja incrementada e/ou adaptada, ao realizá-la novamente.

\section{REFERÊNCIAS}

ALVARENGA, L. Representação do conhecimento na perspectiva da ciência da informação em tempo e espaços digitais. Encontros Bibli: revista eletrônica de Biblioteconomia e Ciência da Informação, Florianópolis, v. 8, n. 15, p. 18-40, 2003.

CAMPOS, M. L. de A.; GOMES, H. E. Organização de domínios de conhecimento e os princípios ranganathianos. Perspectivas em Ciência da Informação, Belo Horizonte, v. 8, n. 2, p. 150-163, jul./dez. 2003.

COLL, C. et al. Os conteúdos na reforma: ensino e aprendizagem de conceitos, procedimentos e atitudes. Porto Alegre, RS: Artmed, 2000, 182 p. 
CYBIS, W.; BETIOL, A. H.; FAUST, R. Ergonomia e usabilidade: conhecimentos, métodos e aplicações. São Paulo: Novatec. 2007.

DAVIES, R. Hierarchical Card Sorting: a tool for qualitative research, 1996. Disponível em: <http://www.mande.co.uk/docs/hierarch.htm>. Acesso em: 18 jun.2014.

FARIA, M. M. de. Card Sorting: noções sobre a técnica para teste e desenvolvimento de categorizações e vocabulários. Revista Digital de Biblioteconomia e Ciência da Informação, Campinas, v.7, n.2, p.1-9, jan./jun. 2010.

GRAHAM, I. UML Tutorial. 2007. Disponível em: 〈http://uml-tutorials.trireme.com/〉. Acesso em: 16 jun. 2014.

HUDSON, W. Card Sorting. In: SOEGAARD, M.; DAM, R. F. (Ed.). The Encyclopedia of Human-Computer Interaction. 2nd ed. Aarhus, Denmark: The Interaction Design Foundation, 2013. Disponível em: <http://www.interactiondesign.org/encyclopedia/card_sorting.html>. Acesso em: 10 maio 2014.

NIELSEN, J. Card Sorting: how many users to test. 2004. Disponível em: <http://www.useit.com/alertbox/20040719.html>. Acesso em: 16 jun. 2014.

ORTEGA, C. D. Contexto de desenvolvimento da Organização da Informação, com enfoque para a Catalogação.Perspectivas em Ciência da Informação, Belo Horizonte, v.18, n.2, p.182-215, abr./jun. 2013.

PADOVANI, S.; RIBEIRO, M. A. Card Sorting: adaptação da técnica para aplicação ao design de sistemas de informação não digitais. Revista Brasileira de Design da Informação, São Paulo, v. 10, n. 3, p. 293 - 312, 2013.

ROCHA, Janicy Aparecida Pereira; SOLANO, Viviane de Oliveira. 2014. Altura: 1024 pixels. Largura: 768 pixels. 300 dpi. 32 BIT CMYK. 1,36 Mb. Formato PNG. Registros de sala de aula.

RODRIGUES, M. E. F.; CAMPELLO, B. S. (Org.) A (re) significação do processo de ensino/aprendizagem em Biblioteconomia e Ciência da Informação: novas abordagens didático-pedagógicas. Niterói, RJ: Intertexto; Rio de Janeiro: Interciência, 2004. 142p. ROSENFELD, L.; MORVILLE, P. Information Architecture for the World Wide Web. 3ed. Sebastopol: O'Reilly, 2006. 528 p.

SÁ, M. I. da F. e. O ensino da disciplina de arquitetura de informação: uma aplicação da técnica de Card Sorting. In: CONGRESSO BRASILEIRO DE BIBLIOTECONOMIA, 
DOCUMENTO E CIÊNCIA DA INFORMAÇÃO, 25, 2013, Florianópolis. Anais... Florianópolis: FEBAB, 2013. Disponível em:

<http://portal.febab.org.br/anais/article/view/1475>. Acesso em: 10 maio 2014.

SANTA ROSA, G.; MORAES, A. de. Design participativo. Rio de Janeiro: Rio Books, 2012. 169 p.

SILVA, A. da; LIMA, G. Revista Interamericana de Bibliotecología. Medellín (Colômbia), v. 34, n. 3, p. 301-312, 2011.

UNIVERSIDADE FEDERAL DE MINAS GERAIS. Programa de Pós-Graduação em Ciência da Informação. PPGCI/UFMG. Resolução n. 05 de 20 de setembro de 2013. Regulamenta o estágio docente de alunos vinculados ao PPGCI/UFMG. Disponível em: <http://ppgci.eci.ufmg.br/o-programa/resolucoes/resolucao-no-03-2013-estagiodocente.pdf/at_download/file>. Acesso em: 01 jun. 2014.

VILELA, R. S. de S., CARVALHO, K. M. de, FAGUNDES, F. Utilização do Card Sorting na implementação de um sistema de Balanced Scorecard para instituições de ensino superior. In: ENCONTRO DE ESTUDANTES DE INFORMÁTICA DO TOCANTINS, 11., 2009, Palmas. Anais... Palmas: Centro Universitário Luterano de Palmas, 2009. p. 233-243. Disponível em: <http://www3.ulbra-to.br/eventos/encoinfo/2009/Anais/Utilizacao_do_Card _Sorting_na_Implementacao_de_um_Sistema_de_Balanced_Scorecard_para_Instituicoes_de Ensino_Superior.pdf >. Acesso em: 6 jun. 2014.

Como citar este documento:

SOLANO, Viviane de Oliveira; ROCHA, Janicy Aparecida Pereira. O Card Sorting no ensino de biblioteconomia: uma experiência em sala de aula. Revista Digital de Biblioteconomia e Ciência da Informação, Campinas, SP, v. 13, n. 2, p. 404-417, maio/ago. 2015. ISSN 1678-765X. Disponível em: <http://periodicos.bc.unicamp.br/ojs/index.php/ rdbci/article/view/8635040>. Acesso em: 31 maio 2015. 


\section{UNIVERSIDADE FEDERAL DE MINAS GERAIS \\ ESCOLA DE CIÊNCIA DA INFORMAÇÃO \\ Arquitetura de Informação e Acessibilidade Digital \\ Modelagem Conceitual a partir dos princípios de Ranganathan \\ Professoras: Janicy Rocha, Viviane Solano - 1ํㅗ semestre de 2014}

\section{APÊNDICE 1}

\section{ATIVIDADE CARD SORTING}

Escrevam os termos abaixo nos cartões, usando os papéis de cores diferentes para cada nível da categorização (p. ex.: as categorias de nível 1 devem ser verdes; todas as subcategorias de nível 2 devem ser azuis; todas as subcategorias de nível 3 em diante devem ser brancas).

Os integrantes de cada grupo deverão discutir entre si qual é a melhor forma de categorizar os itens. Caso seja realmente necessário poderão criar novas categorias, desde que apresentem justificativa. Termos podem ser isolados caso o grupo os considere desnecessários, redundantes ou que não se encaixam em nenhuma categoria, entretanto devem apresentar justificativas para tal.

Os integrantes de cada grupo NÃO DEVERÃO ver como os outros grupos estão fazendo a categorização. O interessante da atividade não é ver quem está certo ou errado, mas comparar os resultados e discuti-los.

Tempo máximo para a atividade: 60 minutos

Tempo máximo para exposição de cada grupo: 10 minutos

1. Ação

2. Alternativo

3. Animação

4. Aventura

5. Biografia

6. Blues

7. Blu-Ray

8. CD

9. Clássico

10. Comédia

11. Contabilidade

12. Corrida

13. Curso

14. Dance

15. Dicionário

16. Didático

17. Documentário

18. Drama
19. DVD

20. Época

21. Esportes

22. Ficção Científica

23. Filmes

24. Filosofia

25. Games

26. Gastronomia

27. Gospel

28. HQs

29. Infantil

30. Infanto-Juvenil

31. Informática

32. Jazz

33. Literatura

34. Livros

35. Luta

36. Manuais
37. MPB

38. Musicais

39. Músicas

40. Orquestra Sinfônica

41. Pocket

42. Policial

43. Rap

44. Reggae

45. Religião

46. Romance

47. RPG

48. Samba

49. Seriados

50. Soul

51. Suspense

52. Trilha Sonora

53. Turismo

54. Educacional 